\title{
Influence of Natural Daylight on Soil Color Description: Assessment Using a Color-Appearance Model
}

\author{
Manuel Sánchez-Marañón* \\ Dep. Edafología y Química Agrícola \\ Univ. de Granada \\ 18071 Granada, Spain

\section{Pedro A. García} \\ Dep. Estadística e Investigación Operativa \\ Univ. de Granada \\ 18071 Granada, Spain \\ Rafael Huertas \\ Javier Hernández-Andrés \\ Manuel Melgosa \\ Dep. Óptica \\ Univ. de Granada \\ 18071 Granada, Spain
}

Soil color is usually described under natural daylight using Munsell charts. Daylight can vary but its effects on the Munsell notation are hardly known. Today, color-appearance models allow quantitative analyses of the perceived color under different lights. Using the CIECAM02 model, we studied the color changes in 238 Munsell chips and 229 soils under 125 types of daylight as well as their effects when matching soil to chips. The different types of daylight were measured from spectral power distributions and color attributes from reflectance spectra. Relationships $(r=-0.94$ to 0.95$)$ between master variables taken from categorical principal-component analyses showed that as daylight becomes bluer (3758-34,573 K), samples with a concave spectrum between 500 and $600 \mathrm{~nm}$ redden while those of a convex spectrum turn yellow. This hue angle change $\left(0.5-29.5^{\circ}\right)$, especially great in slightly chromatic samples $\left(r^{2}=0.90\right)$, was different enough in the soil and chip of most color matches to generate paramerism. The practical implication is that $79 \%$ of the soils had more than one Munsell notation because of daylight changes, although this decreased to $19 \%$ considering only daylight at a solar elevation of $>9^{\circ}$. This finding supports the good practice of pedologists in determining soil color in the central hours of the day; however, $45 \%$ of soils with reflectance spectra close to several chips had Munsell colors either redder or yellower under midday light ( $5933 \pm$ $481 \mathrm{~K}$ ) than under the $\mathrm{C}$ reference illuminant of the Munsell system $(6800 \mathrm{~K})$. Unless the reflectance spectrum of the sample is available, it is not possible to know if soil colors have been correctly denoted or not, or how to compensate for the differences.

$\mathrm{T}$ The description of soil color is a standard part of soil survey and soil research. During field observations, the colors of soils are determined by visually matching specimens to chips of the Munsell soil color charts. The ASTM standard D 1535 (ASTM, 2008) provides a detailed procedure for specifying the Munsell notation of opaque objects such as soil samples. This ASTM standard, like specific soil articles and books (Melville and Atkinson, 1985; Soil Survey Division Staff, 1993), discusses problems inherent to visual color measurement. In accordance with color science (Berns, 2000), variations in the observer, sample state, and lighting conditions may alter the color appearance of soils and chips, and consequently the Munsell notation assigned to a soil sample. Torrent et al. (1983) and Post et al. (1993) calculated standard deviations from 0 to 1.3 with an average of 0.57 for the Munsell hue, value, and chroma judged by different soil scientists on <2-mm soil samples, whereas Baumgardner et al. (1985), Torrent and Barrón (1993), and Sánchez-Marañón et al. (1995) reported differences up to three units in some Munsell parameters of soils evaluated in various physical states. Until this study, however, the light effect in determining soil color had not been quantified.

The standard light to specify the Munsell color notation is daylight (ASTM, 2008). Daylight has been defined for colorimetric applications (International Commission on Illumination, 2004a) by a number of spectral power distributions that can be physically determined (C source) or simulated (D series of illuminants) by artificial sources. Since the 1940s (Newhall et al., 1943), the Munsell system has been referenced to the illuminant $\mathrm{C}$ and International Commission on Illumination (CIE) 1931 standard observer. Natural daylight, however, is a mixture

Soil Sci. Soc. Am. J. 75:984-993

Posted online 18 Apr. 2011

doi:10.2136/sssaj2010.0336

Received 2 Sept. 2010.

*Corresponding author (msm@ugr.es).

(C) Soil Science Society of America, 5585 Guilford Rd., Madison WI 53711 USA

All rights reserved. No part of this periodical may be reproduced or transmitted in any form or by

any means, electronic or mechanical, including photocopying, recording, or any information storage and retrieval system, without permission in writing from the publisher. Permission for printing and for reprinting the material contained herein has been obtained by the publisher. 
of sunlight, skylight (light scattered from the air and clouds), and light reflected from the ground (Lynch and Livingston, 2001). The spectrum of this mixture varies with time, depending on the position of the sun in relation to the site and the prevailing atmospheric conditions (Olesen, 1992; HernándezAndrés et al., 2001; Dogras et al., 2004). Accordingly, while laboratory measurements of soil color can be made under fixed lighting, usually a D65 light source simulator (Post et al., 1994; Sánchez-Marañón et al., 2004; Viscarra Rossel et al., 2006), field measurements (He et al., 2003; Wills et al., 2007) might be affected by changes in the spectral properties and amount of natural daylight. For this reason, the empirical approach for soils is for the field visual color determinations to be performed at solar noon of a clear sunny day when there is a higher proportion of direct white sunlight (Soil Survey Division Staff, 1993; Buol et al., 2003; Schaetzl and Anderson, 2005).

The influence of lighting conditions on perceived color is currently being analytically studied through color-appearance models (Fairchild, 2005). These models provide equations and methodologies to predict the color appearance under specific viewing conditions by transforming physically measurable quantities into perceptual attributes. The CIECAM02 colorappearance model (International Commission on Illumination, $2004 \mathrm{~b}$ ) is the most recent and currently most successfully used in color science (Xiao et al., 2010). This model has also been used as a basis to evaluate color differences because of its embedded uniform color space (Luo et al., 2006) as well as its good performance for large and small color difference evaluation (Melgosa et al., 2008).

Using the CIECAM02 model, this study investigated the influence of natural daylight on soil color descriptions using standard Munsell soil color charts. The specific objectives were: (i) to compute the color appearances of soil samples and color chips under different daylight conditions to assess color changes; and (ii) to compute the color differences between soil samples and color chips to find the best soil chip match, and therefore the Munsell notation of the soil, under each daylight condition.

\section{MATERIALS AND METHODS Natural Daylight Conditions}

From the roof of the University of Granada's Science Faculty $\left(37^{\circ} 11^{\prime} \mathrm{N}, 3^{\circ} 37^{\prime} \mathrm{W}, 680 \mathrm{~m}\right.$ above sea level, southeast Spain), we recorded 125 natural daylight spectra on $10 \mathrm{~d}$, every hour between sunrise and sunset, including different seasons and weather conditions of a normal year (Table 1). The spectral power distributions of hemispheric daylight, i.e., global spectral irradiances on a horizontal surface from direct sunlight (when present) and the entire sky, were measured by a LI-1800 spectroradiometer (LI-COR Inc., Lincoln, NE) with a spectral range from 300 to $1100 \mathrm{~nm}$ in 5-nm steps and uncertainties of $<4 \%$ at $300 \mathrm{~nm}$ and $2 \%$ from 500 to $1100 \mathrm{~nm}$. From daylight spectra and using algorithms of Wyszecki and Stiles (1982), we calculated irradiance by the integration of the spectral curve in the entire interval reported, illuminance in the visible range by photometric equations, and correlated color temperature by the chromaticity coordinates. Finally, the solar elevation (the angle between the direction of the geometric center of the sun's apparent disk from the measurement point and the idealized horizon line) at each moment of daylight was determined from the hour angle in the local sidereal time, the current sun declination, and the local longitude and latitude.

\section{Color Objects: Chips and Soils}

We used 238 standard color chips from a new copy of the Munsell soil color charts 10R, 2.5YR, 5YR, 7.5YR, 10YR, 2.5Y, and 5Y (Munsell Color Company, 2000) and 229 soil samples (Entisols, Inceptisols, Mollisols, and Alfisols) from southeast Spain denoted from 2.5YR to $5 Y$ in hue, 2 to 8 in value, and 1 to 6 in chroma. The spectral reflectance curves of the chips and soils were measured using a Minolta CM-2600d spectrophotometer (Minolta, Osaka, Japan). This instrument has a 52-mm-diameter integrating sphere with an 8 -mm-diameter measuring port, illuminating and viewing geometry $d / 8^{\circ}$, and xenon lamps as the light source. A silicon photodiode array detects the amount of light reflected by the specimen surface from 360 to $740 \mathrm{~nm}$ at $10-\mathrm{nm}$ intervals (repeatability within $0.1 \%$ ). Each color chip was measured at three different points, and the measurements were averaged to provide a single reflectance curve. Soils were also measured by triplicate in $<2$ $\mathrm{mm}$ air-dried samples placed in circular aluminum containers $(15 \mathrm{~mm}$ in diameter and $4 \mathrm{~mm}$ thick). Once the upper open surface was leveled, the measurements were taken directly on this surface. The measure

Table 1. Time and weather conditions during the recording of daylight spectra in Granada (southeast Spain).

\begin{tabular}{|c|c|c|c|c|c|c|}
\hline Spectra & Date & Hour interval & Sky state & Barometric pressure & Temperature & Precipitation \\
\hline no. & & h GMT & & $\mathrm{hPa}$ & ${ }^{\circ} \mathrm{C}$ & $\mathrm{mm}$ \\
\hline 9 & 10 Jan. & $0813-1716$ & overcast and foggy & $698.1-699.7$ & $3.6-9.9$ & - \\
\hline 7 & 30 Jan. & $0828-1732$ & overcast and misty & $688.4-691.8$ & $3.2-9.5$ & 20 \\
\hline 14 & 10 Feb. & $0730-1751$ & clear sunny & $705.6-706.0$ & $1.2-13.8$ & - \\
\hline 10 & 7 Apr. & 0558-1715 & overcast & $694.2-694.8$ & $12.8-15.0$ & 10 \\
\hline 15 & 18 June & 0539-1937 & cloudy with bright spells & $696.8-698.4$ & $20.8-29.9$ & - \\
\hline 15 & 10 July & 0533-1944 & sunny and hazy & $697.7-700.3$ & $22.6-39.0$ & - \\
\hline 13 & 15 Aug. & 0536-1816 & stormy, atmospheric dust & $698.2-698.6$ & $21.5-27.8$ & 35 \\
\hline 16 & 8 Sept. & 0548-1826 & clear sunny & $700.6-701.8$ & $17.2-28.0$ & - \\
\hline 13 & 2 Dec. & $0727-1700$ & clear sunny & $700.4-702.0$ & $3.4-15.4$ & - \\
\hline 13 & 27 Dec. & 0737-1704 & sunny with some clouds & $698.1-700.3$ & $-4.0-10.8$ & - \\
\hline
\end{tabular}


variation (standard deviation) for each chip and soil was $<0.083$ and 1.46 CIELAB units, respectively.

\section{Model Perceptual Attribute Correlates}

The CIECAM02 color-appearance model (International Commission on Illumination, 2004b) fits a variety of recent experimental color data sets, including also current understanding of specific aspects of the human visual system. This model simulates human color perception under a wide variety of visual conditions, providing numerical descriptions of perceptual attributes (Fairchild, 2005): brightness $Q$ (perception of more or less light), lightness $J$ (brightness relative to the brightness of a white), colorfulness $M$ (sensation of more or less chromaticity), chroma $C$ (colorfulness relative to the brightness of a white), saturation $s$ (colorfulness relative to brightness), hue angle $h$ (perceived color), and hue composition $H_{c}$ (hue angle relative to the unique hues of red, yellow, green, and blue). First, we calculated the tristimulus values $X, Y$, and $Z$ of each chip and soil using its reflectance spectrum and each daylight spectral power distribution (Torrent and Barrón, 1993), assuming the CIE 1931 standard observer used by the Munsell system. The same process was followed for the $\mathrm{C}$ illuminant. The CIECAM02 attributes were computed from the tristimulus values, the reference white corresponding to the measured daylight, the illuminance measured each day to compute the luminance of the test adapting field $\left(L_{\mathrm{A}}\right)$, and assuming viewing conditions of the average surround in accordance with the equations provide by the International Commission on Illumination (2004b).

According to Luo et al. (2006), the best structure for predicting color differences from CIECAM02 is a polar space consisting of J, $M$, and $h$. Accordingly, color differences between pairs of samples were calculated as Euclidean distances using the CAM02-UCS equation, the performance of which has recently been proved satisfactory (Melgosa et al., 2008), and is as follows:

$$
\begin{aligned}
& \Delta E^{\prime}=\sqrt{\left(\Delta J^{\prime}\right)^{2}+\left(\Delta a^{\prime}\right)^{2}+\left(\Delta b^{\prime}\right)^{2}} \\
& J^{\prime}=\frac{1.7 J}{1+0.007 J} \\
& M^{\prime}=\frac{1}{0.0228} \ln (1+0.0228 M) \\
& a^{\prime}=M^{\prime} \cos (b) \\
& b^{\prime}=M^{\prime} \sin (b)
\end{aligned}
$$

\section{Data Analyses}

Categorical principal component analysis (Meulman, 1996; Meulman et al., 2004) using the SPSS software version 15.0 (SPSS Inc., Chicago) was applied to the overall data set. This technique reduces the analysis variables to a smaller number of orthogonal components (linear combinations of them) such that they account for as much variation of the data set as possible. In addition, it assesses whether the categories of a nominal supplementary variable differ or not with respect to the aspects measured by the analysis variables. Following Mardia et al. (2000), we used the screen plot to determine the number of components, and the multiple nominal scaling level to fit the categorical variables to the analysis variables in the final solution. In graphical terms, an analysis variable is denoted by a vector, while a categorical variable is represented by category points, each being the centroid of the object scores of the samples.

Several statistical software packages implemented in $\mathrm{R}$ ( $\mathrm{R}$ Development Core Team, 2008) were also used. The circular-statistics package allowed a correct summarized description of the directional data on hue angle and hue composition. The variation of a dependent variable on independent variables was fitted to predictive models by a univariate general linear model (glm function of R-stats), which also plotted the appropriate response surface maps. The general linear model performs both a regression analysis and an analysis of variance to test the effects of other variables (including their interactions) on the means of various groupings of a single dependent variable.

Finally, we wrote an $\mathrm{R}$ protocol to find the Munsell chip most similar to each soil under different daylight conditions, thereby simulating the visual matching of the CIE 1931 standard observer. For each daylight condition and $\mathrm{C}$ illuminant, the software calculated all possible color differences between a soil and all the chips in the Munsell charts, assuming the CAM02-UCS equation (Eq. [1]). By a second routine, the software located the chip with the minimum distance (minimum color difference) to each soil, which was used to assign its Munsell notation to the soil. In the end, we had 125 color matches for each soil as well as another one under the $\mathrm{C}$ reference illuminant for comparison.

\section{RESULTS AND DISCUSSION Component Structure of Daylight and Color}

Great variation was found in the whole data set (Table 2 ). Categorical principal component analysis accounted for $90 \%$ of this variation, with a solution of five components and centroids of day and sample type aligned along daylight and color variables, respectively (Fig. 1a). Solar elevation, irradiance, illuminance, and brightness $Q$ were grouped with large positive loadings $(>0.900)$ in the first principal component (PC1); chroma (0.931), colorfulness (0.879), and saturation (0.870) were loaded on PC2; variables loading high on PC3 were hue angle (0.880) and hue composition (0.875). Lightness defined PC4 with a loading of 0.764 , and correlated color temperature was shared between PC1 (-0.662) and PC5 (0.504). Every day

Table 2. Statistics of the daylight and color parameters measured (229 soils and 238 chips viewed under 125 daylight conditions; $n=58,375$ ).

\begin{tabular}{llllll}
\multicolumn{1}{c}{ Variable } & \multicolumn{1}{c}{ Mean } & \multicolumn{1}{c}{ SD } & \multicolumn{1}{c}{ Min. } & \multicolumn{1}{c}{ Max. } & Median \\
\hline Solar elevation, $^{\circ}$ & 20.3 & 19.5 & -2.2 & 76.2 & 14.3 \\
${\text { Irradiance, } \mathrm{W} / \mathrm{m}^{2}}^{\text {Illuminance, lux }}$ & 172.5 & 206.9 & 0.6 & 810.2 & 85.9 \\
Correlated color temperature, $\mathrm{K}$ & 23726.4 & 28873.5 & 73.1 & 113599.9 & 11740.0 \\
Lightness $(J)$ & 7329.5 & 3400.6 & 3757.8 & 34572.8 & 5993.6 \\
Brightness $(Q)$ & 43.9 & 15.4 & 13.0 & 78.2 & 41.9 \\
Chroma $(C)$ & 235.2 & 88.0 & 45.8 & 511.0 & 225.9 \\
Saturation $(s)$ & 17.6 & 9.3 & 0.3 & 50.1 & 17.1 \\
Colorfulness $(M)$ & 28.7 & 8.1 & 4.4 & 68.4 & 28.2 \\
Hue angle $(h)$ & 19.4 & 10.8 & 0.2 & 66.3 & 17.8 \\
Hue composition $\left(H_{\mathrm{c}}\right)$ & 61.0 & 15.7 & 0.1 & 359.7 & 62.6 \\
\hline
\end{tabular}





Fig. 1. (a) Categorical principal-component analysis for the whole data set $(n=58,375)$, where vectors represent the loadings of the daylight and color variables and black and blank markers are the category points corresponding to 10 dates and the two sample types of color chips and soils $(J=$ lightness, $Q=$ brightness, $C=$ chroma, $s=$ saturation, $M=$ colorfulness, $h=$ hue angle, $H_{\mathrm{c}}=$ hue composition); (b) relationship between correlated color temperature and solar elevation of natural daylight, except for the data on the 18 June and 15 August.

and sample type reflected a similar component structure except in the assignment of correlated color temperature on $\mathrm{PC} 1$ or PC5 (Table 3). The days and sample types, however, appeared different with respect to the aspect measured by the analysis variables; otherwise the centroids of categorical variables in Fig. 1a would be close to the origin (Meulman et al., 2004).

The PC1 indicates that the absolute amount of light reaching (irradiance and illuminance) and reflecting from a sample (brightness) depends on solar elevation. Correlated color temperature, a parameter that recounts the spectral power distribution of any illuminant (International Commission on Illumination, 2004a), also in part proved to be controlled by the solar elevation, i.e., daylight is bluer (greater correlated color temperature) in winter, at sunrise, and at sunset (lower solar elevation), but to some extent likewise appeared independent on PC5, probably indicating the influence of atmospheric conditions. As a result, the days had light with different intensities and spectral profiles, as reflected by the spread of their centroids on PC1 and PC5 in Fig. 1a, and also a variable intensity-spectral relationship, as shown in Table 3. The relationship between solar elevation and correlated color temperature was strong and negative on sunny and overcast days such as on the 30 January. On this day, daylight progressively lost blueness and gained redness from sunrise to midday, and after solar noon it became gradually bluer again until sunset. This relationship, however, was weaker on days with changeable weather (18 June) and even with a positive sign. Specifically on the stormy 15 August, daylight at daybreak was reddish (lower correlated color temperature) because of the presence of high amounts of atmospheric dust and turned bluish toward midday. Therefore, there is a good negative relationship between the quality and intensity of light, except on days with an anomalous atmosphere (Fig. 1b).

On the other hand, PC2 indicates a positive relation among color parameters reflecting the sensation of chromaticity, PC3 groups variables related to perceived hue, and PC 4 is defined by lightness. Soils appeared less chromatic and yellower than chips, their centroids being located in opposite directions on PC2 and PC3 (Fig. 1a), because the colors of the soils covered only a portion of the whole color gamut provided by the Munsell soil charts. The results clearly showed that there are three groups of parameters for specifying soil colors: $J$ and $Q ; M$, s, and $C$; and

Table 3. Rotated component loadings of the five-component categorical principal component analysis solution for 30 January ( $n$ $=3269)$ and 15 August $(n=6071)$.

\begin{tabular}{|c|c|c|c|c|c|c|c|c|c|c|}
\hline \multirow{2}{*}{ Parameter } & \multicolumn{5}{|c|}{30 Jan. } & \multicolumn{5}{|c|}{15 Aug. } \\
\hline & PC1 & PC2 & PC3 & PC4 & PC5 & PC1 & PC2 & PC3 & PC4 & PC5 \\
\hline Solar elevation & $0.943+$ & -0.103 & -0.107 & -0.111 & -0.093 & 0.876 & 0.098 & -0.216 & -0.165 & 0.187 \\
\hline Irradiance & 0.971 & -0.110 & -0.102 & -0.100 & -0.070 & 0.887 & 0.118 & -0.231 & -0.148 & -0.324 \\
\hline Illuminance & 0.971 & -0.110 & -0.102 & -0.100 & -0.070 & 0.874 & 0.115 & -0.224 & -0.140 & -0.328 \\
\hline Correlated color temperature & -0.964 & 0.108 & 0.105 & 0.108 & 0.085 & 0.634 & 0.049 & -0.132 & -0.131 & 0.726 \\
\hline Lightness $(/)$ & 0.163 & -0.070 & 0.633 & 0.644 & 0.332 & 0.262 & 0.116 & 0.494 & 0.742 & -0.038 \\
\hline Brightness $(Q)$ & 0.843 & -0.084 & 0.269 & 0.283 & 0.251 & 0.886 & 0.144 & 0.150 & 0.306 & -0.054 \\
\hline Chroma $(C)$ & 0.236 & 0.896 & 0.326 & -0.086 & 0.060 & -0.083 & 0.955 & 0.225 & -0.069 & 0.001 \\
\hline Saturation $(s)$ & -0.144 & 0.905 & 0.124 & -0.275 & -0.082 & -0.400 & 0.836 & 0.093 & -0.309 & 0.003 \\
\hline Colorfulness $(M)$ & 0.402 & 0.818 & 0.325 & -0.133 & 0.055 & 0.058 & 0.959 & 0.193 & -0.106 & -0.006 \\
\hline Hue angle $(h)$ & -0.037 & -0.417 & 0.795 & -0.304 & -0.168 & 0.254 & -0.245 & 0.889 & -0.218 & 0.017 \\
\hline Hue composition $\left(H_{\mathrm{c}}\right)$ & -0.117 & -0.414 & 0.790 & -0.261 & -0.233 & 0.260 & -0.240 & 0.889 & -0.211 & 0.018 \\
\hline Variance, $\%$ & 42.7 & 24.5 & 18.2 & 7.3 & 2.7 & 35.2 & 24.8 & 19.2 & 8.5 & 7.1 \\
\hline
\end{tabular}

† The strongest correlation of a variable to a component appears in bold. 
$b$ and $H_{\mathrm{c}}$. In addition, there is one group for measuring the absolute quantity of lighting: solar elevation, irradiance, illuminance, and brightness Q. As master variables containing information on the other correlated variables (Mardia et al., 2000), we chose for the subsequent analyses lightness $J$, colorfulness $M$, and hue angle $h$, which are direct attributes of a visual color sensation (Fairchild, 2005), and solar elevation to express light intensity. Correlated color temperature was used to define the light quality because it was not always correlated with light intensity in the same way.

Except for brightness $Q$, highly dependent on solar elevation, the component structures of color and daylight were separated, hindering a more detailed analysis of the effect of daylight on color. It appeared that the internal relations between the daylight variables or the color variables were stronger than the daylightcolor relationship, and the color variation among samples was related to the nature of each sample (absorption and reflection properties) more than to the daylight changes.

\section{Color Changes under Different Daylight Conditions}

An individualized analysis of each sample using master variables made the influence of daylight on color more evident. According to the signs of maximum and minimum coefficients listed in Table 4, which summarizes the correlations for 467 samples, chips and soils consistently decreased in lightness $J$ and colorfulness $M$ with lower solar elevation and higher correlated color temperature. These relationships can be attributed to decreased light reflected from the sample when the incident light has less intensity and a greater proportion of blue, a situation that is consistent with samples having relatively more light absorption in the blue range of the visible spectrum (Fig. 2).

On the other hand, positive and negative correlation coefficients for the hue angle $b$ against solar elevation or correlated color temperature (Table 4) indicate that some samples reddened while others yellowed under the same daylight changes. It should be borne in mind that color results from an interaction between the light and the sample; therefore, samples with different reflectance spectra may be influenced differently by the same change in daylight. The mean correlation coefficient between hue angle and correlated color temperature in all Munsell chips noted 10R $(r=-0.58, n=35), 2.5 \mathrm{YR}(r=-0.54$, $n=37), 5 \mathrm{YR}(r=-0.47, n=33), 7.5 \mathrm{YR}(r=-0.40, n=35)$, 10YR $(r=-0.27, n=36), 2.5 \mathrm{Y}(r=-0.02 n=31)$, and $5 \mathrm{Y}$ $(r=0.25, n=31)$ showed a gradual change of trend linked to the shape of a specimen's spectral reflectance factor (Fig. 2). That is, the bluer the light (greater correlated color temperature), the redder (lower hue angle) the color sample with concave spectra between 500 and $600 \mathrm{~nm}$ (e.g., chip 10R 4/4). The smoothing of the spectrum to a convex shape progressively toned down the light effect until it was inverted. Samples with a convex spectrum (e.g., 5 Y 4/4) yellowed under bluish light and became redder under reddish light.

It is important to ascertain not only the direction of the changes in color attributes $(J, M$, and $h)$, but also the amount of variation. Variation was measured through the standard deviation $(n=125)$ of each sample, which ranged from 0.2 to 0.9 CIECAM02 units for $J$ (on average $0.4, n=467$ ). Colorfulness $M$ and hue angle $h$ had greater variation (on average 3.0 units and $2.6^{\circ}$ ) and also great differences among samples. Especially, the standard deviation in $h$ ranged from 0.5 to 23.2 and 1.0 to $29.6^{\circ}$ among the different chips and soils, respectively. This range suggests again that the nature of each particular sample controls the intensity of the shift in its color caused by a same change in daylight.

The degree of chromaticity of the chips and soils proved to be the main factor controlling their standard deviation in lightness $(\mathrm{SD}-J)$, colorfulness $(\mathrm{SD}-M)$, and hue angle $(\mathrm{SD}-h)$, as indicated by the higher coefficients for the Munsell chroma in Table 5. The influence of chroma was positive in SD-J and



Fig. 2. Several spectral power distributions of natural daylight normalized at $560 \mathrm{~nm}$ with correlated color temperature between $3757 \mathrm{~K}$ (reddish) and 18,390 K (bluish), and reflectance spectra of all standard Munsell color chips of value 4 and chroma 4 from $10 \mathrm{R}$ to $5 \mathrm{Y}$. 
Table 5. Univariate general linear model for the standard deviation of lightness (SD-J), colorfulness (SD-M), and hue angle (SD- $h$ ) in each chip and soil under 125 daylight conditions by Munsell hue $H$, value $V$, and chroma $C$.

\begin{tabular}{|c|c|c|c|c|c|c|c|c|c|}
\hline $\begin{array}{c}\text { Dependent } \\
\text { variable }\end{array}$ & Sample set & Intercept & $H$ & $V$ & C & $H \times V$ & $H \times C$ & $V \times C$ & $r^{2}$ \\
\hline \multirow[t]{2}{*}{ SD-J } & chipst & $0.111(49,065)$ & $0.020(214)$ & $0.010(109)$ & ) $0.090(1235)$ & $-0.003(3)$ & $-0.009(18)$ & $0.005(7)$ & 0.91 \\
\hline & soilsł & -0.703 & 0.038 & 0.148 & 0.190 & -0.008 & -0.002 & -0.008 & 0.94 \\
\hline \multirow[t]{2}{*}{ SD-M } & chips & $0.558(55243)$ & $-0.110(11)$ & $-0.083(4)$ & $1.098(3543)$ & ) $0.028(2)$ & $0.004(1)$ & $-0.015(2)$ & 0.96 \\
\hline & soils & 0.316 & -0.008 & 0.094 & 1.036 & 0.001 & 0.005 & -0.058 & 0.99 \\
\hline \multirow[t]{2}{*}{ SD- $h$} & chips & $24.565(165)$ & $-4.329(49)$ & $1.890(19)$ & $-5.630(103)$ & $-0.088(1)$ & $0.946(9)$ & $-0.235(4)$ & $0.69 \S$ \\
\hline & soils & 74.667 & -3.921 & 1.573 & -15.440 & 0.102 & 0.723 & -0.676 & 0.53 \\
\hline
\end{tabular}

† Regression coefficients $(n=238)$ and $F$ statistics (in parentheses) by levels of $H(1=10 \mathrm{R}, 2=2.5 \mathrm{YR}, 3=5 \mathrm{YR}, 4=7.5 \mathrm{YR}, 5=10 \mathrm{YR}, 6=2.5 \mathrm{Y}, 7$ $=5 Y), V(1=2,2=2.5,3=3,4=4,5=5,6=6,7=7,8=8)$ and $C(1=1,2=2,3=3,4=4,5=6,6=8)$.

₹ Regression coefficients $(\boldsymbol{n}=229)$ on spectrophotometric measurements of $H$ (numerical notation), $V$, and $C$.

$\S r^{2}=0.90$ for the model: $\mathrm{SD}-h=52.03+1.86 C^{2}+0.95 H^{2}-0.16 H^{2} C-19.45 C-13.36 H+2.71 C H+2.13 V-0.47 V C$.

SD- $M$ and the surface maps in response to the Munsell notation of chips (Fig. 3) accordingly showed that as the samples became more chromatic, there were greater changes associated with $J$ and $M$. In addition, the Munsell value and hue were less important interaction factors in the variation of $J$. For the same Munsell chroma, lighter or redder chips had a slightly greater SD-J, as reflected by the curvature of the response surfaces and positive and negative regression coefficients for value $\times$ chroma $(0.005$, Table 5) and hue $\times$ chroma $(-0.009)$. Also, there was an evident effect, now negative, of the sample's Munsell chroma on SD- $b$ (Fig. 3). The daylight influenced the quantitative change in $h$, especially in samples with a chroma value of $<3$, but even more so when they were also red (10R-5YR). Polynomial models of the second or third degree from the analysis variables Munsell hue, value, chroma (e.g., footnote of Table 5), in agreement with complex response surfaces (Fig. 3), explained a greater variability in SD- $h\left(r^{2}=0.90\right)$ than the first degree model with interactions $\left(r^{2}=0.69\right)$, for which coefficients are listed in Table 5 .

Because the color changes under different daylight conditions have been demonstrated, the practical question now is: do these color changes have enough significance to cause inaccuracies in the soil color description using Munsell soil color charts?

\section{Matching Soil to Chips under Different Daylight Conditions}

The lowest CAM02-UCS color differences (Eq. [1]) allowed matching of each soil to a standard color chip under different natural daylight conditions. The results (Table 6) indicated that changes in daylight cause changes in the soilchip color matches, which agrees with what has sometimes been reported visually by soil scientists (Soil Survey Division Staff, 1993; Torrent and Barrón, 1993). Only $21.4 \%$ of our overall soil set had an invariant match, whereas $78.6 \%$ had between two and six different matches. The reason for this is a certain metameric behavior, whereby a soil and a chip having different spectral reflectance may match under one daylight condition but not under another. This phenomenon in soil-chip color matches, which need not be visually perfect to be acceptable, is called paramerism (Marcus, 1998). The color differences between a soil and several chips (two to six in our case) should be attenuated or
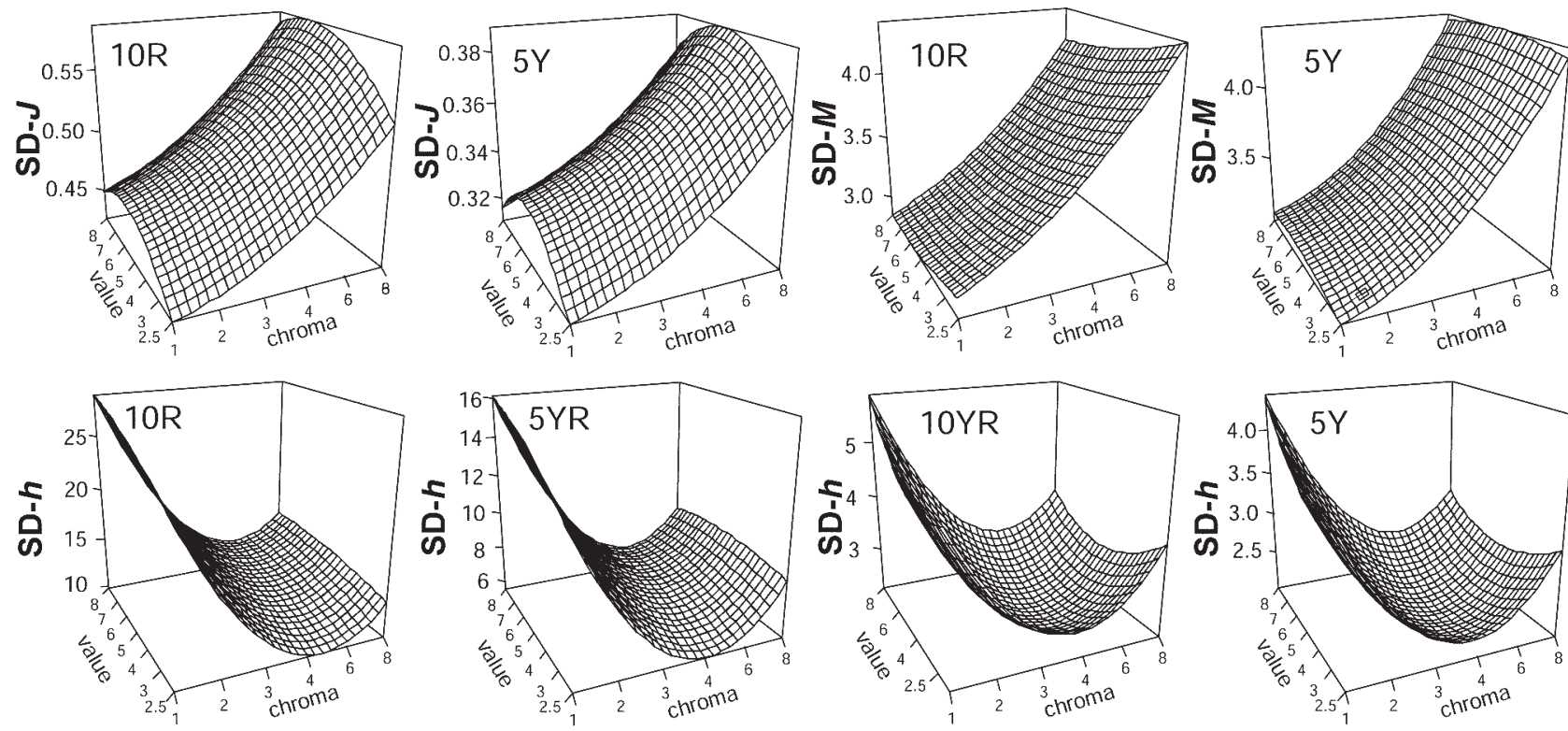

Fig. 3. Response surface maps of the standard deviation of lightness (SD-J), colorfulness (SD-M), and hue angle (SD- $h$ ) modeled for some Munsell soil color charts viewed under 125 daylight conditions. 
Table 6. Percentage of soils $(n=229)$ having one, two, three, four, five, and six different color matches with Munsell chips under 125 natural daylights.

\begin{tabular}{|c|c|c|c|c|c|c|c|c|c|c|c|c|}
\hline \multirow{2}{*}{ Soils } & \multicolumn{3}{|c|}{ Spectrophotometric color } & \multicolumn{6}{|c|}{ Frequency of each color match } & \multicolumn{3}{|c|}{ Notation differencet } \\
\hline & Hue & Value & Chroma & First & Second & Third & Fourth & Fifth & Sixth & $\Delta$ Hue & $\Delta$ Value & $\Delta$ Chroma \\
\hline$\%$ & & & & & & - $\%$ & & & & & & \\
\hline 21.4 & $19.0 \mathrm{~A}(0.1) \neq$ & $=4.4 \mathrm{~A}(0.1)$ & $3.0 \mathrm{~A}(0.1)$ & $100(0.0)$ & & & & & & 0 & 0 & 0 \\
\hline 23.2 & $19.1 \mathrm{~A}(0.4)$ & $4.7 \mathrm{AB}(0.2)$ & $2.8 \mathrm{AB}(0.1)$ & $94.4(1.1)$ & $5.6(1.1)$ & & & & & $2.2(0.3)$ & $0.0(0.0)$ & $0.8(0.1)$ \\
\hline 34.9 & 20.2 B (0.3) & $5.1 \mathrm{~B}(0.1)$ & $2.5 \mathrm{~B}(0.1)$ & $88.1(1.5)$ & $10.5(1.4)$ & $1.4(0.3)$ & & & & $3.0(0.4)$ & $0.3(0.1)$ & $1.4(0.1)$ \\
\hline 14.4 & 20.4 B (0.5) & $5.0 \mathrm{~B}(0.1)$ & $2.0 \mathrm{C}(0.1)$ & $79.9(3.0)$ & $15.9(2.5)$ & $3.4(0.9)$ & $0.8(0.0)$ & & & $4.2(0.6)$ & $0.4(0.1)$ & $1.8(0.1)$ \\
\hline 5.7 & 21.0 B (0.8) & $4.7 \mathrm{AB}(0.2)$ & $1.9 \mathrm{C}(0.3)$ & $72.3(4.5)$ & $24.9(4.4)$ & $1.1(0.1)$ & $0.9(0.1)$ & $0.8(0.0)$ & & $6.5(0.8)$ & $0.9(0.3)$ & $1.6(0.2)$ \\
\hline 0.4 & $23.3 \mathrm{AB}$ & $5.2 \mathrm{AB}$ & $1.2 \mathrm{ABC}$ & 81.6 & 15.2 & 0.8 & 0.8 & 0.8 & 0.8 & 10 & 1 & 3 \\
\hline
\end{tabular}

† Absolute values

₹ Means with standard deviations in parentheses; means followed by different letters are significantly different (Fisher's LSD, $P<0.05)$.

exaggerated according to the spectral power distribution of the light so that different color matches are possible.

Paramerism causes different color notations of the same soil sample when it is determined by Munsell charts under different daylight conditions. The number of notations statistically increased as soils were yellower and less chromatic, and especially noteworthy was the Munsell hue shift (between 2.5 and 10 Munsell units, Table 6). The mean Munsell hue assigned to soils $(n=229)$ increased (yellower notation) or decreased (redder notation) when the correlated color temperature of daylight also increased or decreased, respectively, as occurred mostly at lower solar elevations (Fig. 4). Conversely, although with some irregularities, the Munsell hue notation was more homogeneous at higher solar elevations when the correlated color temperature was more stable.

In examining the minimum solar elevation for which a second Munsell notation has a $<5 \%$ probability of appearing, we found $9^{\circ}$. Of the 229 soils evaluated under 75 daylight conditions with solar elevations of between 9 and $76^{\circ}$ (correlated color temperature $5933 \pm 481 \mathrm{~K}$ ) occurring between approximately 0800 and 1700 h GMT in Granada (southeast Spain), 19\% had more than one Munsell notation. In addition, almost half of the soils (45\%) had some Munsell notation during this daily period that did not correspond to that viewed under the $\mathrm{C}$ illuminant, this latter being the reference light for the Munsell system. Thirty-eight percent of the notations $(n=17,175)$ failed and, of these, 35\% had a Munsell hue notation that was either yellower or redder than using the $\mathrm{C}$ illuminant (Fig. 5). Two reasons can explain these differences.

First, the natural daylight at midday was usually a bit less bluish and more reddish than the $\mathrm{C}$ illuminant (Fig. 6). We found natural daylight conditions more similar to $\mathrm{C}$, according to its correlated color temperature (close to $6800 \mathrm{~K}$; International Commission on Illumination, 2004a), when the solar elevation was around $10^{\circ}$ (Fig. 1b), i.e., approximately $1 \mathrm{~h}$ after sunrise and before sunset. It is also noteworthy that overcast days had daylight with correlated color temperatures closer to that of the $\mathrm{C}$ illuminant during the central hours of the day and, consequently, more accurate Munsell notations than on clear sunny days (Fig. 5a). Second, the spectral reflectance factor of soil is frequently near two chips from different hue charts (Fig.
6). Soils and chips redden or become yellow according to the light, but also to a different degree according to their reflectance, which decides the better match in each case. Daylight notably yellowed the Munsell notation of many of our soil samples that had a concave spectrum between 500 and $600 \mathrm{~nm}$ (red soils, on the left of 10YR in Fig. 5b), while some other samples having a convex spectrum (yellow soils, on the right of 10YR) were noted as being somewhat redder than when using the $\mathrm{C}$ illuminant.

The influence of the reflectance spectra hampers systematic compensation for referring the Munsell hue determination to its standard C illuminant. Thus, the regression of the Munsell hue notation under the $\mathrm{C}$ illuminant $\left(H_{\mathrm{C}}\right)$ on the Munsell hue notation under natural daylight $\left(H_{\mathrm{ND}}\right)$ showed a considerable uncertainty $\left(H_{\mathrm{C}}=-5.50+1.24 H_{\mathrm{ND}} ; r^{2}=0.60\right)$ because the daylight did not have the same consequences for all the soil-chip matches. On the contrary, the models for Munsell value $\left(V_{\mathrm{C}}=\right.$ $\left.0.05+0.98 V_{\mathrm{ND}} ; r^{2}=0.97\right)$ and chroma $\left(C_{\mathrm{C}}=0.12+0.93 C_{\mathrm{ND}}\right.$; $\left.r^{2}=0.97\right)$ indicated a minor discrepancy between the notations under the $\mathrm{C}$ illuminant and natural daylight and high reliability to make compensations because of the illuminant change.



Fig. 4. Mean color hue notation of the 229 soils vs. the correlated color temperature and solar elevation of each daylight condition used in the color matching with Munsell charts. 

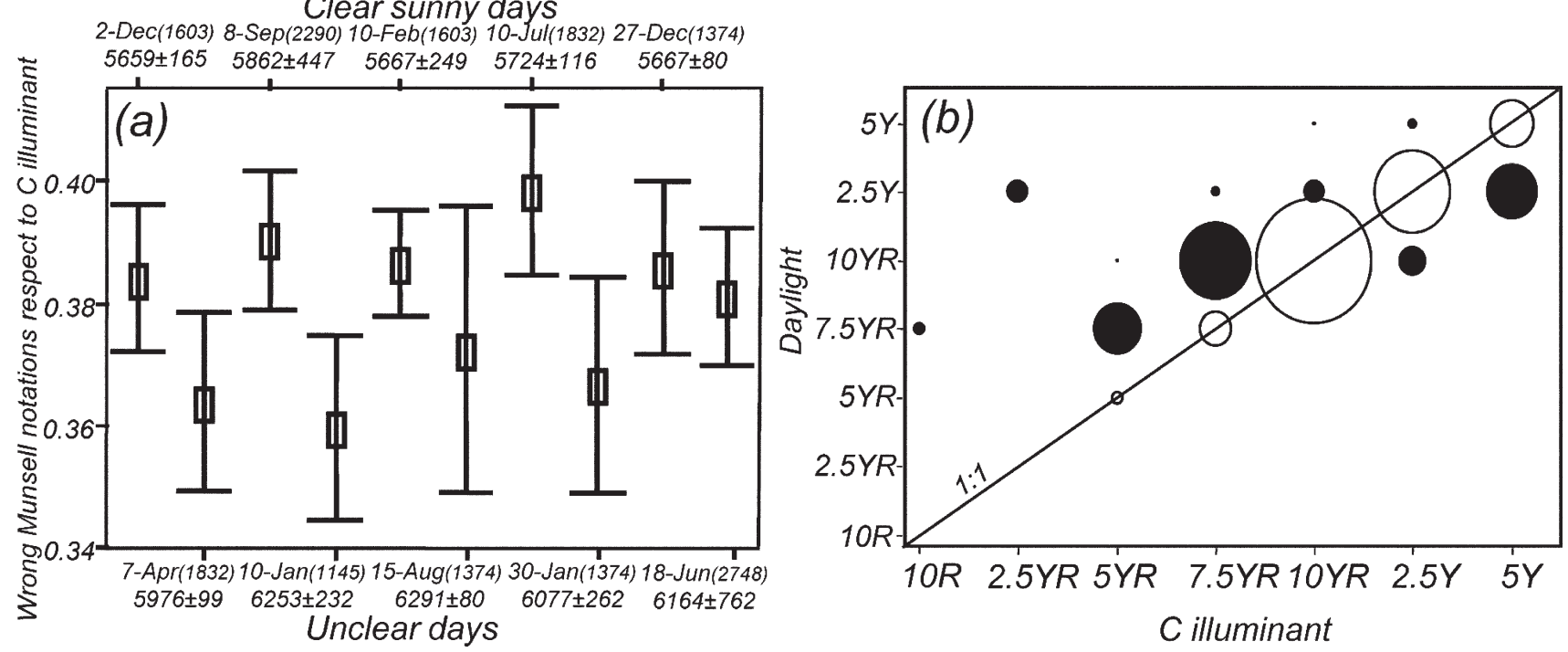

Fig. 5. Comparison of the Munsell soil color notations under daylight conditions at solar elevation $>9^{\circ}(n=17,175)$ with respect to those under the reference $C$ illuminant: (a) mean and error bars of the right (0) and wrong (1) notations in each day, indicating the number of notations (in parentheses) and correlated color temperature; (b) right (blank markers) and wrong (black markers) hue notations, indicating the number of notations by the marker size.

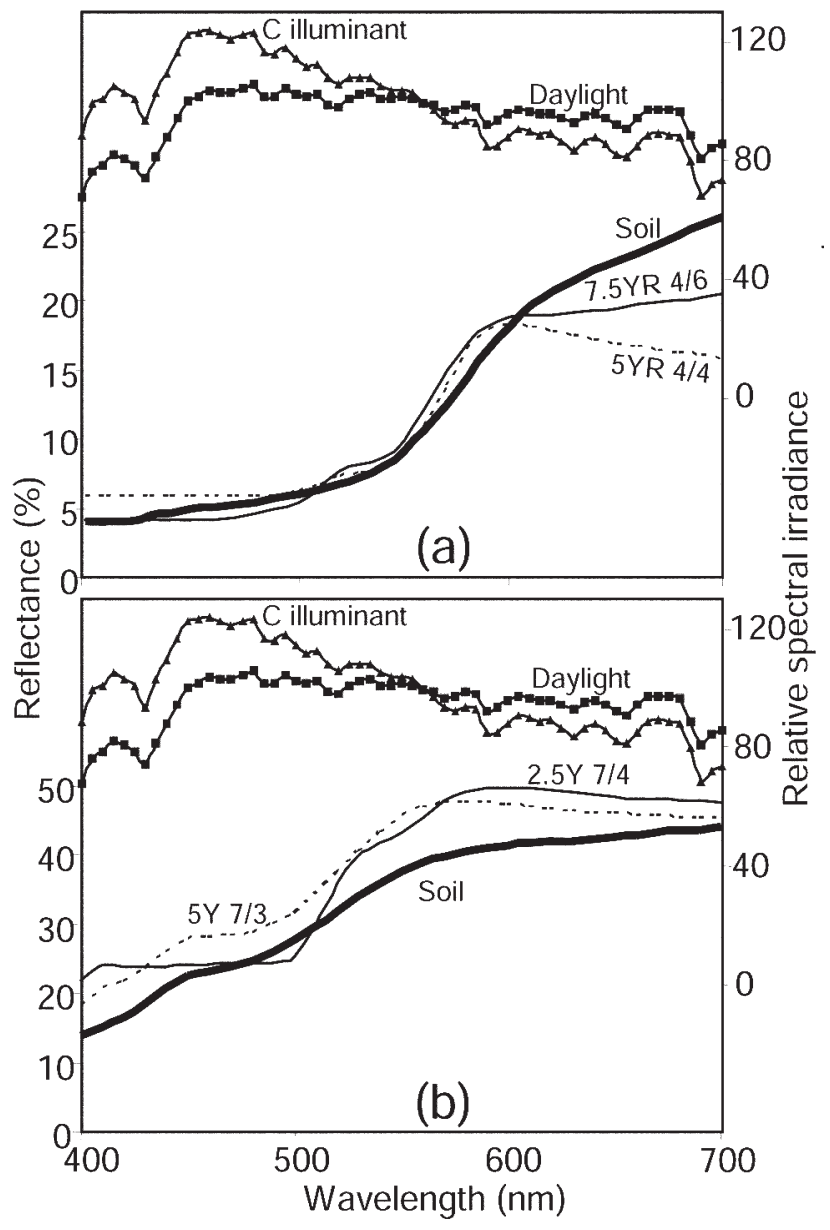

Fig. 6. Spectral power distribution of the $\mathrm{C}$ illuminant $(6800 \mathrm{~K})$ and daylight at solar noon of a clear sunny day $(5602 \mathrm{~K})$, and reflectance spectra of the nearest Munsell chip to a soil with (a) concave and (b) convex spectra when viewed under the $\mathrm{C}$ illuminant (broken line) or daylight (solid line).

\section{CONCLUSIONS}

The changes in daylight reddened or yellowed soils and chips according to their reflectance spectra. As daylight lost intensity and gained blue, which occurs with decreasing solar elevation $\left(76-0^{\circ}\right)$ and increasing correlated color temperature (3758$34,573 \mathrm{~K}$ ), the samples with concave reflectance spectra between 500 and $600 \mathrm{~nm}$ reddened while those with a convex spectrum yellowed. Although the mean change in the CIECAM02 hue angle $b$ was $2.6^{\circ}$, it increased to $29.0^{\circ}$ in samples of low chromaticity. The samples also decreased slightly in lightness $J$ and colorfulness $M$ (averaging 0.4 and 3.0 CIECAM02 units).

With the same daylight change, each soil and chip changed its color hue to a different degree according to its reflectance spectrum, which changes the soil-chip color match. Accordingly, different Munsell notations may appear for the same soil. The change in Munsell notation depends on the amount of variation in daylight and the spectral resemblance between soil and chip. From sunrise to sunset, the reading for color hue in most soils (79\%) can vary between one and four Munsell charts, i.e., 2.5 to 10 units of hue redder or yellower, depending on the day and hour. This hue variation increases when the chroma of the soil decreases. When the solar elevation is $>9^{\circ}$, the natural daylight is more stable ( $5933 \pm 481 \mathrm{~K}, n=75)$ and the possibility of finding more than one Munsell notation per soil is dramatically reduced (19\%). This means that matching the soil color early or late in the day will result in greater errors than in the middle of the day.

Soil scientists have generally believed that the natural daylight conditions during the central hours of clear and sunny days are ideal to determine soil color in the field. Our results demonstrate that certainly the probability of different Munsell notations for a given soil is reduced under these conditions, but about one third of the notations in this period could be incorrect relative to the $\mathrm{C}$ illuminant (the reference daylight 
for the Munsell system). When the soil's reflectance spectrum resembles the spectra of several chips and daylight conditions at midday are substantially less bluish than the C illuminant, the reading of color in red (10R-7.5YR) and yellow (2.5Y-5Y) soils one or more intervals of hue yellower and redder, respectively, than under the $\mathrm{C}$ illuminant. In contrast, if the soil spectrum is unequivocally close to a single chip, there is no influence of daylight. In practice, there is no way to predict what soil needs compensation for the differences unless the spectral reflectance is measured. Consequently, soil color determination in the field is only a preliminary approach; accurate specifications require instrumental measurements under controlled lighting in the laboratory. If a visual soil-chip color-matching technique is used in the laboratory, the use of a color cabinet with a source having a spectral power distribution as close as possible to the $\mathrm{C}$ illuminant is encouraged.

In the field, soil color would probably be more accurately noted if the standards used in the color matching were better adapted to the natural daylight conditions. The $\mathrm{C}$ illuminant is a poor representation of natural daylight and the chips from the Munsell soil color charts are also affected by daylight changes. Possibly the $\mathrm{C}$ illuminant should be replaced as the reference by different representative phases of daylight such as CIE illuminants D65 or D50, which show a better fit to the correlated color temperatures of daylight conditions as measured in this work. In addition, a new set of color chips developed from these daylight phases, and having high color consistency across a range of illuminants, should be proposed in future studies.

With the present standard, the best solution to overcome inaccuracies is to perform visual judgments only under natural conditions in which the spectral power distribution of daylight is closest to that of the $\mathrm{C}$ illuminant. Working at the hours with solar elevations around $10^{\circ}$ (i.e., approximately $1 \mathrm{~h}$ after sunrise or before sunset) is the best, because it prevents the interference of daylight conditions that are too bluish and reddish with respect to the $\mathrm{C}$ illuminant. We caution, however, that our current results may be quite specific, and they can probably be reliably applied only to places at intermediate latitudes. The accuracy in Munsell notations at midday may also be improved by making judgments preferably on overcast days, because they have daylight values more similar to the $\mathrm{C}$ illuminant than sunny days. When the visual soil color does not match any available Munsell chip (a very frequent situation in soil science practice), we can suspect a parameric behavior, and only personal experience may help in choosing the optimum Munsell notation.

\section{ACKNOWLEDGMENTS}

This work has been supported by research projects FIS2007-64266 and FIS2010-19839 of the Ministerio de Educación y Ciencia (Spain). We thank Mr. David Nesbitt for improving the English editing.

\section{REFERENCES}

ASTM. 2008. D1535-08: Standard practice for specifying color by the Munsell system. ASTM Int., West Conshohocken, PA.

Baumgardner, M.F., L.F. Silva, L.L. Biehl, and E.R. Stoner. 1985. Reflectance properties of soils. Adv. Agron. 38:1-44. doi:10.1016/S0065-
$2113(08) 60672-0$

Berns, R.S. 2000. Billmeyer and Saltzman's principles of color technology. 3rd ed. John Wiley \& Sons, New York.

Buol, S.W., R.J. Southard, R.C. Graham, and P.A. McDaniel. 2003. Soil genesis and classification. 5th ed. Iowa State Univ. Press, Ames.

Dogras, C.K., M.P. Ioannidou, and D.P. Chrissoulidis. 2004. Analytical study of the changes in the color of daylight due to sulfate droplets and soot grains in the atmosphere. J. Quant. Spectrosc. Radiat. Transf. 84:223-238. doi:10.1016/S0022-4073(03)00179-1

Fairchild, M.D. 2005. Color appearance models. 2nd ed. John Wiley \& Sons, New York.

He, X., M.J. Vepraskas, D.L. Lindbo, and R.W. Skaggs. 2003. A method to predict soil saturation frequency and duration from soil color. Soil Sci. Soc. Am. J. 67:961-969. doi:10.2136/sssaj2003.0961

Hernández-Andrés, J., J. Romero, J.L. Nieves, and R.L. Lee. 2001. Color and spectral analysis of daylight in southern Europe. J. Opt. Soc. Am. A: Opt. Image Sci. Vis. 18:1325-1335. doi:10.1364/JOSAA.18.001325

International Commission on Illumination. 2004a. Colorimetry. 3rd ed. CIE Publ. 15:2004. CIE Central Bureau, Vienna.

International Commission on Illumination. 2004b. A colour appearance model for colour management systems: CIECAM02. CIE Publ. 159:2004. CIE Central Bureau, Vienna.

Luo, M.R., G. Cui, and C. Li. 2006. Uniform colour spaces based on CIECAM02 colour appearance model. Color Res. Appl. 31:320-330. doi:10.1002/ col.20227

Lynch, D.K., and W. Livingston. 2001. Color and light in nature. 2nd ed. Cambridge Univ. Press, Cambridge, UK.

Marcus, R.T. 1998. The measurement of color. p. 31-96. In K. Nassau (ed.) Color for science, art and technology. Elsevier Science, Amsterdam.

Mardia, K.V., J.T. Kent, and J.M. Bibby. 2000. Multivariate analysis. 7th ed. Academic Press, London.

Melgosa, M., R. Huertas, and R.S. Berns. 2008. Performance of recent advanced color-difference formulas using the standardized residual sum of squares index. J. Opt. Soc. Am. A: Opt. Image Sci. Vis. 25:1828-1834. doi:10.1364/JOSAA.25.001828

Melville, M.D., and G. Atkinson. 1985. Soil colour: Its measurement and its designation in models of uniform colour space. J. Soil Sci. 36:495-512. doi:10.1111/j.1365-2389.1985.tb00353.x

Meulman, J.J. 1996. Fitting a distance model to homogeneous subsets of variables: Points of view analysis of categorical data. J. Classif. 13:249-266. doi: 10.1007/BF01246101

Meulman, J.J., A.J. van der Kooij, and W.J. Heisser. 2004. Principal component analysis with nonlinear optimal scaling transformations for ordinal and nominal data. p. 49-70. In D. Kaplan (ed.) The SAGE handbook of quantitative methodology for the social sciences. Sage Publ., Thousand Oaks, CA.

Munsell Color Company. 2000. Munsell soil color charts. Munsell Color Co., Baltimore, MD.

Newhall, S.M., D. Nickerson, and D.B. Judd. 1943. Final report of the O.S.A. subcommittee on the spacing of the Munsell colors. J. Opt. Soc. Am. 33:385-418. doi:10.1364/JOSA.33.000385

Olesen, T. 1992. Daylight spectra $(400-740 \mathrm{~nm})$ beneath sunny, blue skies in Tasmania. Aust. J. Ecol. 17:451-461. doi:10.1111/j.1442-9993.1992. tb00828.x

Post, D.F., R.B. Bryant, A.K. Batchily, A.R. Huete, S.J. Levine, M.D. Mays, and R. Escadafal. 1993. Correlation between field and laboratory measurements of soil color. p. 35-50. In J.M. Bigham and E.J. Ciolkosz (ed.) Soil color. SSSA Spec. Publ. 31. SSSA, Madison, WI.

Post, D.F., E.H. Horvath, W.M. Lucas, S.A. White, M.J. Ehasz, and A.K. Batchily. 1994. Relations between soil color and Landsat reflectance on semiarid rangelands. Soil Sci. Soc. Am. J. 58:1809-1816. doi:10.2136/ sssaj1994.03615995005800060033x

R Development Core Team. 2008. R: A language and environment for statistical computing. Available at www.R-project.org (verified 4 Mar. 2011). R Foundation for Statistical Computing, Vienna.

Sánchez-Marañón, M., G. Delgado, R. Delgado, M.M. Pérez, and M. Melgosa. 1995. Spectroradiometric and visual color measurements of disturbed and undisturbed soil samples. Soil Sci. 160:291-303. doi:10.1097/00010694199510000-00008

Sánchez-Marañón, M., M. Soriano, M. Melgosa, G. Delgado, and R. Delgado. 
2004. Quantifying the effects of aggregation, particle size and components on the colour of Mediterranean soils. Eur. J. Soil Sci. 55:551-565. doi:10.1111/j.1365-2389.2004.00624.x

Schaetzl, R., and S. Anderson. 2005. Soils: Genesis and geomorphology. Cambridge Univ. Press, New York.

Soil Survey Division Staff. 1993. Soil survey manual. Agric. Handbk. 18. U.S. Gov. Print. Office, Washington, DC.

Torrent, J., and V. Barrón. 1993. Laboratory measurement of soil color: Theory and practice. p. 21-30. In J.M. Bigham and E.J. Ciolkosz (ed.) Soil color. SSSA Spec. Publ. 31. SSSA, Madison, WI.

Torrent, J., U. Schwertmann, H. Fechter, and F. Alférez. 1983. Quantitative relationships between soil color and hematite content. Soil Sci. 136:354-
358. doi:10.1097/00010694-198312000-00004

Viscarra Rossel, R.A., B. Minasny, P. Roudier, and A.B. McBratney. 2006. Colour space models for soil science. Geoderma 133:320-337. doi:10.1016/j. geoderma.2005.07.017

Wills, S.A., C.L. Burras, and J.A. Sandor. 2007. Prediction of soil organic carbon content using field and laboratory measurements of soil color. Soil Sci. Soc. Am. J. 71:380-388. doi:10.2136/sssaj2005.0384

Wyszecki, G., and W.S. Stiles. 1982. Color science: Concepts and methods, quantitative data and formulae. 2nd ed. John Wiley \& Sons, New York.

Xiao, X.D., M.R. Luo, C.J. Li, and G.W. Hong. 2010. Colour appearance of room colours. Color Res. Appl. 35:284-293. doi:10.1002/col.20575 